trudes beyond the anus. The similarity be- brane, by which it was completely closed. tween the action of the levator ani, and that On the division of this membrane, a conof the levator palpebræ superioris, induced siderable quartity of menstrual blood esProfessor Langenbeck to perform the same caped, after which the fluctuating swellings operation for intus-susceptio recti, as for in the abdomen disappeared. 'The ragina entropium. After replacing a considerable was enormously distended, and it was now portion of prolapsed gut, this surgeon evident that the blood collected in it, had pinched up the skin in several parts of the produced the swellings so evident on the orifice of the auus, and removed the folds sides of the abdomen. The pain in the thus formed with a scissars. The wounds bowels increased after the operation, and healed in fourteen days, and the prolapsus notwithstanding a strict antiphlogistic treatnever returned.

The cure must have been effected by an increased contraction of the levatores recti. Dupuytren has adopted a similar mode of treating prolapsus ani, in several cases, with great success.

ON A PRETERNATURAL STZE OF THE MOUTH.

Christian Weknstedt was born with a very large mouth, and, in his seventeenth year, the transverse diameter of the mouth amounted to six inches and a half. The mother believed that the child had been born with its foot in the mouth; but as this was not observed at the time, it does not appear very probable. The tongue was so large, that it always hung between the teeth, and, according to the mother, was in that position at the time the child was born. To what cause could this unusual size of the mouth be attributed? Professor Langenbeck conceives, that the size of the tongue prevented the complete formation of the mouth, since it extended from one ear to the other, just as in the seventh week of pregnancy. By the removal of the callous edges of the more internal parts of the mouth, and the use of sutures, this part of the body was restored to its natural size and shape.

\title{
TWO CASES OF IMPERFORATE HYMEN.
}

\section{BY PROFESSOR LANGENBECK of}

A girl, sixteen years of age, who had never menstruated, complained of a swelling on each side of the abdomen in the region of the ovaries, which never disappeared, but became larger, attended with severe pain in the part, whenever symptoms similar to those of approaching menstruation made their appearance, On examination, I found the fluctuation so distinct, that it might readily have been taken for hydrops orarii. The abdomen was tender on pressure, particularly in the neighbourhood of the swelling. In the vagina there was a thick mem-

* Langenbeck's Bibliothek, vol. iv, pt. 3. + Ibid. fifth day. On examination after death, seve. ral gangrenous spots were observed on the intestines, as well as a considerable quantity of lymph. The vagina appeared like a blown up sac. In this girl, the inflammatory affection was probably caused by the long suppression of the menstrual blood. The operation was, no doubt, the exciting cause, from which we may conclude, that in cases of supressed menstruation from the same cause, it ought not to be so long deferred.

A similar case came under my notice in a girl of nineteen years of age, who had never mentruated. On examining the or. gans of generation, the orifice of the urethra was found situated an inch lower down than natural ; the hymen was of a semilunar shape; the opening in it was so small that a small probe could scarcely be introdued. The septum between the vagina and the urethra was completely wanting, so that the two formed one canal. The bladder, in fact, opened directly into the ragina. I could discover no traces of the uterus, and after the hymen had been perforated, no menstrual discharge came away. The urine at first was passed involuntarily, but this soon disappeared. I believe no uterus existed in this case.

I have in my possession a child with spina bifida in which the entrance into the vagina is blocked up by the hymen; and the uterus, Fallopian tubes and ovaries are wanting. Betwen the bladder and rectum the semilunar folds of Douglas are situated, and between these the hymen. The labia majora are naturally formed. When the ragina is quite closed, and the hymen does not present to the touch a fluctating feel after symptoms similar to those of approaching menstruation have made their appearance, we may conclude that the uterus is wanting.

In another child, the hymen is wanting. Between the labia majora, there are three apenings, the superior of which is the orifice of the urethra ; below this, the opening into the vagina, and still lower down, the opening of the rectum. 